\title{
Gelişmiş ve Gelişmekte Olan Ülkelerde Telekomünikasyon Yatırımları ve Doğrudan Yabancı Sermaye Yatırımları İlişkisi
}

\author{
Relationship Between Telecommunication Investments and Foreign Direct Investments \\ in Developing and Developed Countries
}

Cengiz AYTUN ${ }^{1}$, Cemil Serhat AKIN², Okyay UÇAN

\section{ÖZET}

\begin{abstract}
Bu çalışmanın hedefi telekomünikasyon yatııımları ile doğrudan yabancı sermaye yatırımları arasındaki ilişkinin panel veri analizi ile araştırımasıdır. Veriler 7 gelişen ve 14 OECD üyesi ülke için 1975-2009 yıllarını kapsayacak şekilde gruplandırılmıştır. Önceki çalışmalardan farklı olarak uygulamada yatay kesit bağımlılığı ve heterojenlik göz önünde bulundurulmaktadır. Elde edilen bulgular her iki ülke grubu için de telekomünikasyon yatıımlarının ülkeye gelen doğrudan yabancı sermaye yatıımlarının pozitif ve anlamlı belirleyicisi olduğunu ortaya koymaktadır. Ayrıca bu etkinin gelişmiş ülkelerde gelişmekte olan ülkelerden daha büyük olduğu görülmektedir. Bu açıdan doğrudan yabancı sermaye yatırımlarını telekomünikasyon yatırımları aracılığı ile ülkeye çekmeyi hedefleyen politikaların etkili olacağı söylenebilir.
\end{abstract}

Anahtar kelimeler: Telekomünikasyon Yatırımları; FDI; OECD; Gelişen Ülkeler;

\section{GiRiş}

Günümüzde doğrudan yabancı sermaye yatırımlarının gelişen ülkeler için büyümeyi hızlandıran önemli bir etken olduğu kabul edilmektedir. Bu anlamda 1980 'li yıllardan sonra çoğu gelişmekte olan ülke için bu yatırımları çekebilmek en önemli politika hedeflerinden birisi olmuştur (Gholami vd., 2005). Literatürde ülkeye gelen doğrudan yabancı sermaye yatırımları ile beşeri sermaye, düşük ücretler, doğal kaynaklar ve politik istikrar gibi etkenler arasında yaygın bir şekilde ilişki kurulmaktadır. Ancak özellikle $2000^{\prime}$ li yillardan sonra enformasyon ve telekomünikasyon teknolojilerinin gündemde daha çok yer işgal etmesi ile birlikte bu teknolojilerin doğrudan yabancı sermaye yatırımlarını kendine çekme gücü daha çok sorgulanmaya başlanmıştır (Colecchia ve Schreyer, 2002; Pohjola, 2002; Choi, 2003). İnternetin yaygınlaşması ile telekomünikasyon teknolojilerinin etkileri de hissedilir hale gelmiştir. Enformasyon ve telekomünikasyon teknolojilerinin doğrudan yabancı

\begin{abstract}
The aim of this study is to investigate the relationship between foreign direct investments and telecommunication investments by using panel data analysis. Data' are classified into 7 developing and 14 OECD countries for during the period 1975-2009. Different from the previous studies, cross sectional dependency and heterogeneity conditions are considered in the analysis. The results indicate that telecommunication investments are positive and significant determiners of foreign direct investments for both country groups. Additionally, this effect is more prominent in developing countries than developed countries. Accordingly, it may be put forward that the policies which aim to attract foreign direct investment via telecommunication investment will be effective.
\end{abstract}

Keywords: Telecommunication Investments; FDI; OECD; Emerging Economies

sermaye yatırımlarını arttırıcı etkileri çeşitli faktörlere bağlanmaktadır. Illk olarak artan telekomünikasyon ile arama ve yabancı piyasalara giriş maliyetleri düşmektedir. İkinci olarak telekomünikasyon teknolojileri sayesinde birçok aracı ortadan kalkmakta tüketicilere doğrudan ulaşılabilmektedir. Üçüncü olarak telekomünikasyon ve özellikle internet sayesinde yatırım yapılacak ülke şeffaflaşarak iş ilişkileri kurabilmek kolaylaşmaktadır. Bu anlamda yabancı yatırımcıların telekomünikasyon altyapısı daha güçlü ülkelere yatırım yapması beklenmektedir (Choi, 2003; Gholami vd., 2005). Ülkelerin gelişme süreci içerisinde gelişen ülkelerde enformasyon teknolojileri ile doğrudan yabancı sermaye yatırımları arasında anlamlı ve pozitif bir ilişki beklenirken, gelişmiş ülkelerde pozitif etkinin daha da güçlenmesi beklenmektedir (Alexander, 2010).

Mevcut literatür incelendiğinde bu alandaki çalışmaların zaman serisi ve birinci nesil panel veri araçlarının ötesine geçmediği görülmektedir (Gholami vd., 2005; Soper vd., 2006; Economou, 2008; Alexan-

\footnotetext{
'Dr., Çukurova Üniversitesi, Kozan MYO, Finans-Bankacılık ve Sigortacılık Bölümü, cengiza@cu.edu.tr

${ }^{2}$ Yrd. Doç. Dr., Mustafa Kemal Üniversitesi, iiBF, İktisat Bölümü, csakin@mku.edu.tr

${ }^{3}$ Yrd. Doç. Dr., Niğde Üniversitesi, iỉBF, İktisat Bölümü, okyayu@hotmail.com
} 
der, 2010; Ketteni vd., 2010). Uygulamalı literatürdeki eksikliği gidermek üzere bu çalışmanın temel amacı telekomünikasyon yatırımları ile ülkeye gelen doğrudan yabancı sermeye yatırımları arasındaki nedensellik ilişkisinin, yatay kesit bağımlılığı, homojenlik, birim kök ve eşbütünleşme analiz araçları ile araştırılmasıdır. Uygulamada kullanılan veriler Dünya Bankası (WB), Birleşmiş Milletler Ticaret ve Kalkınma Konferansı (UNCTAD) ve Dünya Telekomünikasyon Birliğinin (ITU) veri tabanlarından, 1975-2009 yıllarını kapsayacak şekilde elde edilmiştir. 7 gelişen ve 14 OECD üyesi gelişmiş ülkenin seçimindeki temel ölçüt telekomünikasyon yatırımlarına ilişkin verilerin 19752009 dönemini için bulunabilir olmasıdır.

Ampirik uygulama üç aşamadan oluşmaktadır. Birinci aşamada yatay kesit bağımlılığı (Breusch ve Pagan, 1980; Pesaran, 2004; Pesaran vd., 2008) ve homojenlik testleri (Pesaran ve Yamagata, 2008) uygulanmaktadır. İkinci aşamada serilere IPS (Im vd., 2003) ve CADF (Pesaran, 2007) birim kök testleri uygulanarak durağanlıkları araştırımaktadır. Üçüncü aşamada serilerinin uzun dönemli bir eşbütünleşme ilişkisi içerisinde olup olmadıkları Westerlund ve Edgerton (2007) testi ile araştırılmıştır. Ardından eşbütünleşik seriler Fully Modified OLS (Pedroni, 2000) Dinamik SUR (Mark vd., 2005) tahmincileri ile tahmin edilmiştir. Son aşamada Dumitrescu ve Hurlin (2012) tarafından heterojen ve yatay kesit bağımlılığı bulunan panel veri modelleri için geliştirilen test ile seriler arasındaki kısa dönemli nedensellik dinamikleri araştırılmıştır.

Elde edilen bulgular her iki ülke grubu için de telekomünikasyon yatırımlarının ülkeye gelen doğrudan yabancı sermaye yatırımlarının pozitif ve anlamlı belirleyicisi olduğunu ortaya koymaktadır. Ayrıca bu etkinin gelişmiş ülkelerde gelişmekte olan ülkelerden daha büyük olduğu görülmektedir. Bu açıdan doğrudan yabancı sermaye yatırımlarını telekomünikasyon yatırımları aracılığı ile ülkeyle çekmeyi hedefleyen politikaların etkili olacağı söylenebilir.

Çalışmanın kalan kısmı şöyle tasarlanmıştır. İkinci bölümde konu ile ilgili literatür özeti verilmiştir. Üçüncü bölümde çalışmada kullanılan veri seti ve yöntem tanıtılmaktadır. Dördüncü bölüm, yapılan ampirik analizleri içermektedir. Son bölümde ise çalışmada ulaşılan sonuçlar özetlenmekte ve değerlendirilmektedir.

\section{LITERATÜR}

Ampirik çalışmaların büyük bir kısmında yapılacak yatırımların temel belirleyicileri olarak kişi başına GSYiH, dış ticaret, sermaye akımları, dış borç, kamu kesimi borçlanma gereksinimi, enflasyon ve faiz oranı gösterilmektedir (Tablo 1). Bu değişkenler geleneksel yatırım teorisine göre çıktı büyümesi ve faiz oranı, hükümet politikalarına bağlı olarak kamu harcamaları, kamu borçlanması ve enflasyon olarak kategorize edilirken açık ekonomi koşullarında ticaret değişkeni, dış borçlar ve karaborsa aktivitelerini içermektedir (Uçan ve Öztürk, 2011). Neoklasik yatırım teorisi reel çıktı büyüme oranının yatırım ile pozitif yönlü olarak ilişkili olduğunu iddia etmektedir. Çünkü reel çıktı büyüme oranının yatırımcıların aradığı çıktı için toplam talepteki değişimleri gösterdiğini belirtmektedirler. Ampirik çalışmalar da bu yönde bulgular içerip, yüksek büyüme oranlarının daha yüksek yatıım değerlerine neden olduğunu doğrulamaktadırlar (Fielding, 1997, 1993; Greene ve Villanueva, 1991; Wai ve Wong, 1982). 
Tablo 1: Literatür Taraması

\begin{tabular}{|c|c|c|c|}
\hline Yazar(lar) & Metot & Ülke(ler) & Sonuç \\
\hline Agarwal(1980) & $\begin{array}{l}\text { Literatür tara- } \\
\text { ması }\end{array}$ & Tüm ülkeler & $\begin{array}{l}\text { Doğrudan yabancı yatıımın belirleyicileri hakkında genel bir çalışma } \\
\text { yapılmıştır. }\end{array}$ \\
\hline $\begin{array}{l}\text { Terpstra ve Yu } \\
\text { (1988) }\end{array}$ & $\begin{array}{l}\text { Panel veri } \\
\text { analizi }\end{array}$ & $\begin{array}{l}\text { USA } \\
(1972-1984)\end{array}$ & $\begin{array}{l}\text { Yabancı yatırım yapan firmalar gözüyle incelenen makalede, firmala- } \\
\text { rın ülkelerin coğrafik özelliklerine bakmadıklarını, kendi ülkesindeki } \\
\text { firmaları takip ettikleri, yatıım yaparken oligopolistik davranışlar ser- } \\
\text { giledikleri üzerinde durulmuştur. }\end{array}$ \\
\hline $\begin{array}{l}\text { Loree ve Guisinger } \\
\text { (1995) }\end{array}$ & $\begin{array}{l}\text { En küçük ka- } \\
\text { reler }\end{array}$ & $\begin{array}{l}\text { ABD } \\
(1977-1982)\end{array}$ & $\begin{array}{l}\text { Politik istikrar, kültürel farklılıklar, kişi başına düşen gayri safi milli ha- } \\
\text { sıla ve altyapı değişkenlerinin doğrudan yabancı yatırımı etkiledikleri } \\
\text { yönünde tutarlı sonuçlara ulaşılış̧ır. }\end{array}$ \\
\hline Chen(1996) & $\begin{array}{l}\text { Havuzlanmış } \\
\text { yatay kesit ve } \\
\text { zaman serisi }\end{array}$ & $\begin{array}{l}\text { Çin } \\
(1979-1992)\end{array}$ & $\begin{array}{l}\text { İşgücü ücretlerinin doğrudan yabancı yatırımı etkileyen bir unsur } \\
\text { olmadığını ve bölgesel farlılıkların doğrudan yabancı yatırımların } \\
\text { belirleyicileri olduğu sonucuna ulaşmışlardır. }\end{array}$ \\
\hline $\begin{array}{l}\text { Borensztein, Gregorio- } \\
\text { ve ve Lee } \\
\text { (1998) }\end{array}$ & $\begin{array}{l}\text { (Görünürde } \\
\text { İlişkisiz Regres- } \\
\text { yon)SUR }\end{array}$ & $\begin{array}{l}69 \text { seçilmiş } \\
\text { gelişmekte olan } \\
\text { ülke } \\
(1970-1989)\end{array}$ & $\begin{array}{l}\text { Çalışmada yazarlar yabancı doğrudan yatırımın büyüme üzerindeki } \\
\text { pozitif etkisinin, sermaye birikiminin arttırılmasından daha fazla } \\
\text { etkinlik sağlayacağı sonucuna ulaşmışlardır. }\end{array}$ \\
\hline $\begin{array}{l}\text { Cheng ve Kwan } \\
\text { (1999) }\end{array}$ & $\begin{array}{l}\text { Dinamik panel } \\
\text { regresyon }\end{array}$ & $\begin{array}{l}\text { Çin } \\
\text { (1985-1995) }\end{array}$ & $\begin{array}{l}\text { Yazarlar, bölgedeki doğrudan yabancı yatırım dengesinde bir yakın- } \\
\text { samaya rastlamaz iken, doğrudan yabancı yatırım sapmalarında bir } \\
\text { yakınsama olduğunu belirtmişlerdir. }\end{array}$ \\
\hline Chakrabarti(2001) & $\begin{array}{l}\text { En küçük ka- } \\
\text { reler }\end{array}$ & 135 Ülke & $\begin{array}{l}\text { Kişi başına düşen gayri safi milli hasıla doğrudan yabancı yatıımı } \\
\text { belirleyen potansiyel bir değişkendir. }\end{array}$ \\
\hline Asiedu(2002) & $\begin{array}{l}\text { En küçük ka- } \\
\text { reler }\end{array}$ & $\begin{array}{l}\text { Afrika } \\
(1970-1999)\end{array}$ & $\begin{array}{l}\text { Daha fazla yatırım getirisi ve daha iyi altyapı ile büyüme üzerinde } \\
\text { doğrudan yabancı yatırımın etkisi pozitif olacaktır. }\end{array}$ \\
\hline Choi (2003) & $\begin{array}{l}\text { En küçük Ka- } \\
\text { reler }\end{array}$ & $\begin{array}{l}53 \text { seçilmiş ülke } \\
\text { (1995) }\end{array}$ & $\begin{array}{l}\text { Ülkede internet kullanımı \% } 10 \text { arttığında ülkeye gelen FDI miktarı \% } \\
2 \text { oranında artmaktadır. }\end{array}$ \\
\hline $\begin{array}{l}\text { Gholami, Lee ve Hesh- } \\
\text { mati(2005) }\end{array}$ & $\begin{array}{l}\text { Zaman serisi, } \\
\text { Panel veri } \\
\text { analizi }\end{array}$ & $\begin{array}{l}23 \text { seçilmiş ülke } \\
(1976-1999)\end{array}$ & $\begin{array}{l}\text { Gelişmiş ülkelerde telekomünikasyon yatırımlarından doğrudan ya- } \\
\text { bancı sermaye yatırımlarına bir ilişki bulunurken, gelişmekte olan } \\
\text { ülkelerde nedensellik ters yöndedir. }\end{array}$ \\
\hline Ndikuman(2006) & $\begin{array}{l}\text { Dinamik kore- } \\
\text { lasyon modeli }\end{array}$ & $\begin{array}{l}30 \text { güney Afrika } \\
\text { ülkesi }\end{array}$ & $\begin{array}{l}\text { Finansal gelişmenin ekonomik büyümeye olumlu etkileri sermaye bi- } \\
\text { rikimi ve doğrudan yabancı yatırımlarla mümkündür. }\end{array}$ \\
\hline $\begin{array}{l}\text { Soper, Demirkan, Goul } \\
\text { ve Louis } \\
(2006)\end{array}$ & $\begin{array}{l}\text { En Küçük Ka- } \\
\text { reler }\end{array}$ & $\begin{array}{l}29 \text { seçilmiş ülke } \\
(1993-2003)\end{array}$ & $\begin{array}{l}\text { Gelişmekte olan ülkelerde telekomünikasyon yatırımlarının gelecek } \\
\text { doğrudan yatırım seviyelerinde güçlü bir etkiye sahip olduğu sonu- } \\
\text { cuna ulaşılmıştır. }\end{array}$ \\
\hline Economou(2008) & $\begin{array}{l}\text { Tablo analizi ve } \\
\text { teorik }\end{array}$ & $\begin{array}{l}125 \text { seçilmiş ülke } \\
(2002-2007)\end{array}$ & $\begin{array}{l}\text { Yazar, telekomünikasyon yatırımlarının yabancı doğrudan yatırımın } \\
\text { önemli bir belirleyicisi olduğu sonucuna ulaşmıştır. }\end{array}$ \\
\hline $\begin{array}{l}\text { Veeramacheneni, } \\
\text { Vogel ve Ekanaya- } \\
\text { ke(2008) }\end{array}$ & Eşbütünleşme & $\begin{array}{l}\text { Hindistan } \\
(1970-2005)\end{array}$ & $\begin{array}{l}\text { Telekomünikasyon, doğrudan yabancı yatırımlar ve büyüme arasında } \\
\text { çift yönlü ilişkiler bulunmuştur. }\end{array}$ \\
\hline Alexander(2010) & $\begin{array}{l}\text { Panel veri } \\
\text { analizi }\end{array}$ & $\begin{array}{l}232 \text { seçilmiş ülke } \\
(2000-2008)\end{array}$ & $\begin{array}{l}\text { Ülkelerin yatırım gelişim yolunda doğrudan yabancı yatırımın en } \\
\text { önemli belirleyicisi ve anahtar rolde olan değişken telekomünikasyon } \\
\text { yatırımlarıdır. }\end{array}$ \\
\hline $\begin{array}{l}\text { Ketteni, Kottaridive } \\
\text { Mamuneas } \\
\text { (2010) }\end{array}$ & $\begin{array}{l}\text { Parametrik } \\
\text { olmayan Tek- } \\
\text { nikler }\end{array}$ & $\begin{array}{l}15 \text { seçilmiş ülke } \\
(1980-2004)\end{array}$ & $\begin{array}{l}\text { Gelişmiş ve gelişmekte olan ülkeler örnek alınarak yapılan telekomü- } \\
\text { nikasyon yatırımlarının işgücü üretkenliğini arttırdığı bulunmuştur. }\end{array}$ \\
\hline
\end{tabular}

Kaynak: Yazarlar tarafından oluşturulmuştur.

Enformasyon teknolojilerindeki gelişimle birlikte telekomünikasyon yatırımları gibi yeni değişkenler de yatırımı belirleyen temel değişkenler arasında yerini almaktadır. Literatür incelendiğinde (Tablo 1) 2005 sonrası dönemde telekomünikasyon yatırımlarının doğrudan yabancı sermaye yatırımları üzerine olan etkisinin daha çok incelendiği görülmektedir (Gholami vd., 2005; Soper vd., 2006; Economou, 2008; Ale- xander, 2010; Ketteni vd., 2010). Alexander'a (2010) göre ülkeler azgelişmişlikten gelişmişliğe doğru yol alırken ülkeye gelen doğrudan yabancı sermaye yatırımlarının da niteliği değişmektedir. Gelişmenin ilk aşamalarında ülkeye gelen yatırımlar daha çok hammadde üretimine yönelik iken giderek sanayi yatırımları ve inovasyona, son aşamada ise artan ölçüde bilgi ekonomisi alanlarına yönelmektedir. Azgelişmiş 
ülkelerde enformasyon teknolojileri ile doğrudan yabancı sermaye yatırımları arasında anlamlı ilişki görülmezken gelişen ülkelerde ilişki pozitife dönmektedir. Gelişmiş ülkelerde ise pozitif etki daha da güçlenmektedir.

\section{VERI VE YÖNTEM}

Enformasyon ve telekomünikasyon teknolojilerine ilişkin ampirik çalışmaların önündeki en önemli kısıtlardan birisi yapılan yatırımlara ilişkin uzun dönemli bir veri setinin bulunamamasıdır (Aytun ve Akın, 2014). Pek çok çalışma yatırımları temsil etmek üzere sabit ve mobil telefon hat sayılarını temsili değişkenler olarak kullanma yolunu izlemektedir. Bu çaIışmada temsili serilerin kullanılması yerine doğrudan doğruya telekomünikasyon yatırımlarının (TELINV) kullanılması tercih edilmiştir. Bütün değişkenler seviye değerleri ile ifade edilmiştir (Tablo 2 ).

FDI değişkeni ülkeye gelen doğrudan yabancı sermaye yatırımları olarak tanımlanmıştır. TRADE değişkeni ülkenin yapmış olduğu ihracat ve ithalat değerlerinin toplamıdır. GSYiH sabitken artan dış ticaret hacmi aynı zamanda ülkenin dış dünyaya açıklığını da temsil etmektedir. Ülkeye gelen doğrudan yabancı sermaye yatırımları ile ticaret hacminin pozitif ilişki içerisinde olması beklenmektedir. Analizde kullanılan ikinci değişken GSYiH'dır. Ekonomik performansın göstergesi olarak GSYiH (GDP) 2005 yılı sabit fiyatları ile (USD) ifade edilmiştir.

Tablo 2: Uygulamada Kullanılan Seriler

\begin{tabular}{|l|l|c|}
\hline Kod & Açıklama & Kaynak \\
\hline FDI & Doğrudan Yabancı Sermaye Yatırımları (Gelen yatırımlar) (USD) & WB*\& UNCTAD** \\
\hline TELINV & Telekomünikasyon Yatırımları (USD) & ITU*** $^{* *}$ \\
\hline GDP & Gayrisafi Yurtiçi Hasıla (USD) & WDI $^{*}$ \\
\hline TRADE & İhracat + İthalat (USD) & WDI $^{*}$ \\
\hline
\end{tabular}

Not: Seriler 2005 yılı baz alınarak sabit fiyatlarla ifade edilmiştir.

*The World Bank, World Development Indicators: http://data.worldbank.org/data-catalog/world-development-indicators (Erişim: 01.02.2014)

** United Nations Conference on Tradeand Development, UNCTAD-STATS http://unctadstat.unctad.org/ ReportFolders/ reportFolders.aspx?sCS_referer=\&sCS_ChosenLang=en (Erişim: 01.02.2014)

**** World Telecommunication Union, World Telecommunication ICT Indicators 2011 (CD-ROM)

Uygulamada kullanılan veriler Dünya Bankası (WB), Birleşmiş Milletler Ticaret ve Kalkınma Konferansının (UNCTAD) çevrimiçi veri tabanlarının yanı sıra Dünya Telekomünikasyon Birliğinin (ITU) ICT göstergeleri CDROM'u kullanılarak bir araya getirilmiştir. Gelişmiş ve gelişmekte olan ülkelerin seçimindeki temel ölçüt telekomünikasyon yatırımlarına ilişkin verilerin 1975-2009 dönemi için bulunabilir olmasıdır. Telekomünikasyona ilişkin verilerin bulunabildiği 7 gelişen (E-7) ve 14 OECD üyesi (OECD-14) ülke ${ }^{1}$ için uygulamanın yapılmasına karar verilmiştir.

Telekomünikasyon yatırımlarının doğrudan yabancı sermaye yatırımlarına olan etkisini ampirik olarak araştırmak üzere bu çalışma Gholami vd. (2005) tarafından oluşturulan modeli temel almıştır. Böylece aşağıdaki model (Denklem 1) doğrudan yabancı sermaye yatırımları üzerinde telekomünikasyon yatırımlarının etkisini ölçmek üzere oluşturulmuştur.

$$
\begin{gathered}
\mathrm{FDI}_{\mathrm{i}, \mathrm{t}}=\alpha_{\mathrm{i}}+\beta_{1 \mathrm{i}} \operatorname{TELINV}_{\mathrm{i}, \mathrm{t}}+\beta_{2 \mathrm{i}} \mathrm{GDP}_{\mathrm{i}, \mathrm{t}}+\beta_{3 \mathrm{i}} \operatorname{TRADE}_{\mathrm{i}, \mathrm{t}}+\varepsilon_{\mathrm{i}, \mathrm{t}} \\
(\mathrm{i}=1,2,3, \ldots, \mathrm{N}) ;(\mathrm{t}=1,2,3, \ldots, \mathrm{T})
\end{gathered}
$$

Denklemde FDI ülkeye gelen doğrudan yabancı sermaye yatırımlarını, TELINV ülkede telekomünikasyona yapılan yatıım harcamalarını, GDP gayri safi yurt içi hasılayı, TRADE ise ithalat ve ihracat toplamından oluşan dış ticaret hacmini ifade etmektedir.

$\mathrm{Bu}$ çalışmada yöntem olarak panel yatay kesit bağımlılığı, homojenlik, birim kök ve eşbütünleşme analizleri kullanılarak, ülkeye gelen doğrudan yabancı sermaye yatırımları ile telekomünikasyon yatırımları arasındaki ilişki araştırılmaktadır. Çalışmada serilere ilişkin yatay kesit bağımlılığının test edilmesinde Breusch ve Pagan (1980) $C D_{L M 1}$, Pesaran (2004) $C_{D_{L M 2}}$ - $\mathrm{CD}_{\mathrm{LM} 3}$ ve Pesaran vd. (2008) $\mathrm{LM}_{\text {adj }}$ lagrange çarpanı testleri kullanılmıştır. Her bir test için $\mathrm{H}_{0}$ hipotezi "Yatay kesit bağımlıı̆ı̆ı yoktur" şeklindedir. $\mathrm{N}$ sabit T sonsuza giderken $C D_{\mathrm{LM} 1}$ testi kullanılabilirken $\mathrm{N}$ sayısının da artması durumunda kullanılamaz. Bu sorunu gidermek üzere Pesaran (2004) tarafından $\mathrm{CD}_{\mathrm{LM} 2}(\mathrm{~T}>\mathrm{N})$ ve $C D_{L M 3}(T>N, T<N)$ test istatistikleri geliştirilmiştir. ilerleyen yıllarda Pesaran vd. (2008) $\mathrm{CD}_{\mathrm{LM} 1}$ testinin $\mathrm{H}_{0}{ }^{\prime} 1$ kabul etme eğiliminde olduğunu göstermişlerdir. Sorun $L_{\text {adj }}$ testi ile düzeltilmiş olup, test istatistiği $T>N$ iken kullanılabilmektedir. Panel veri uygulamalarında araştırılması gereken bir diğer konu ise oluşturulan modellere ilişkin katsayıların homojen olup olmadıklarıdır. Katsayılar heterojen iken homojen oldukları varsayılarak havuzlanmış EKK ile modellerin tahmin edilmesi, katsayıların sapmalı olmasına neden olmak- 
tadır (Baltagi, 2005). Katsayıların homojenliğinin test edilmesinde kullanılan en temel yöntem standart $\mathrm{F}$ testidir. Sabit $\mathrm{N}$ ve $\mathrm{T}>\mathrm{N}$ durumunda geçerli olan yaklaşıma göre, her bir ülke için sistem olarak EKK ile tahmin edilen zaman serilerinde eğim katsayılarının beraberce sıfır olduğun yönündeki hipotez Wald sınaması ile test edilir (Pesaran ve Yamagata, 2008).

Birim kök testleri heterojenlik ve yatay kesit bağımlılığı durumlarının varlığında, söz konusu durumları göz önünde bulundurabilmelidir. Heterojen panellerde IPS (Im vd., 2003) birim kök testi yaygın olarak kullanılmaktadır. Söz konusu test zaman serisinde kullanılan ADF testinin panel veriye uyarlanmış bir versiyonudur. IPS testi her ne kadar birimler arası heterojenliği göz önünde bulundursa da yatay kesit bağımlılığı koşullarında geçerli değildir. Bu durumu dikkate almak üzere Pesaran (2007) tarafından geliştirilen CADF (Cross Sectionally Augmented Dickey Fuller) testinde her bir t dönemi için zaman ortalamalarını hesaplanarak, bu ortalamalar yatay kesit bağımlılığına neden olan ortak faktör olarak modele dahil edilmektedir. Ayrıca her bir birim ya da ülke için elde edilen birim kök test istatistiklerinin ortalaması alınarak panele özgü CADF test istatistiği üretilmektedir.

Makroekonomik serilere ilişkin araştırmalarda seriler seviye değerlerinde durağan değillerken doğrusal bileşimleri durağan olabilmektedir. Bu çalışmada Westerlund ve Edgerton (2007) tarafından heterojen ve yatay kesit bağımlılığı koşullarında kullanılabilen panel eşbütünleşme testi kullanılacaktır. Test McCoskey ve Kao (1998) tarafından geliştirilen Lagrange çarpanı testine dayanmaktadır.

$$
L M_{N}^{+}=\frac{1}{N T^{2}} \sum_{i=1}^{N} \sum_{t=1}^{T} \hat{\hat{w}_{i}} \hat{s}_{i t}^{2}
$$

Test istatistiğinin hesaplanmasında kullanılan hata terimlerinin kısmi toplamları $\left(s_{i t}{ }^{2}\right)$ ve uzun dönem varyanslar $\left(\hat{w}_{i}^{2}\right)$ Fully Modified OLS yöntemi ile tahmin edilen eşbütünleşme modelinden elde edilmektedir. Hesaplanan $\mathrm{LM}_{\mathrm{N}}{ }^{+}$test istatistiği (Denklem 2) ile eşbütünleşmenin mevcut olduğu yönünde kurulan $\mathrm{H}_{0}$ hipotezi sınanmaktadır. Testte yatay kesit bağımlılığı durumunda bootstrap ile hesaplanan kritik değerler kullanılmaktadır. Gerçekleştirilen Monte Carlo simülasyonları testin küçük örneklem durumlarında da kullanılabileceğini ortaya koymaktadır.

Panel veri analizinde eşbütünleşik serilere ilişkin tahminde Fully Modified OLS (FMOLS) yaygın olarak kullanılmaktadır (Pedroni, 2000). Ancak bu tahminci ülkeler için eşanlı olarak tahmin edilen modelde heterojenliği göz önünde bulundurabilirken yatay kesit bağımlıığını dikkate alamamaktadır. Mark vd. (2005) tarafından geliştirilen panel görünürde ilişkisiz regresyon tahmincisi (DSUR) ise zaman ve yatay kesiti boyutlarındaki bağımlılıkları bir arada dikkate almaktadır. DSUR tahmincisinde içsellik sorunu modele ek- lenen gecikme ve öncüllerle giderilmektedir. Ayrıca tahmincinin kullanılabilmesi için zaman boyutunun yatay kesit boyutundan büyük olması gerekmektedir.

Ekonomik değişkenler arasındaki eşbütünleşme ilişkisinin yanı sıra değişkenler arasındaki nedensellik ilişkisi de önemli bir araştırma konusudur. Bu çalışmada Dumitrescu ve Hurlin (2012) tarafından heterojen panel veri modelleri için geliştirilen nedensellik testi kullanılmaktadır. Söz konusu test Granger (1969) tarafından heterojen panel veriye uygulanmış nedensellik testinin bir versiyonudur. Gerçekleştirilen Monte Carlo deneyleri test istatistiklerinin küçük örneklemlerde ve yatay kesit bağımlılığı durumunda kullanılabileceğini göstermektedir. Sıfır hipotezi altında paneldeki hiçbir birim için nedensellik ilişkisinin olmadığı varsayılmaktadır. Bu hipotez HNC (homogenous noncausality) olarak adlandırımaktadır. Alternatif hipotez panel içerisindeki birimlere özgü nedenselliklerin heterojen yapıda olduğunu varsaymaktadır. Uygulamada her bir yatay kesit için $H_{0}: \beta_{i}=0$ hipotezi sırası ile test edilmektedir. Ardından elde edilen $\mathrm{N}$ adet standart Wald istatistiğinin $\left(W_{i j}\right)$ ortalaması alınarak panel için $W_{N, T}{ }^{H N C}$ istatistiği (Denklem 3) hesaplanmaktadır (Dumitrescu ve Hurlin, 2012).

$$
\begin{aligned}
& W_{N, T}^{H N C}=\frac{1}{N} \sum_{i=1}^{N} W_{i, T} \\
& Z_{N, T}^{H N C}=\sqrt{\frac{N}{2 K}}\left(W_{N, T}^{H N C}-K\right) \rightarrow N(0,1)(4)
\end{aligned}
$$

Nedenselliğin var olmadığına dair kurulan sıfır hipotezi altında her bir birim için elde edilen Wald istatistik değerleri K serbestlik derecesinde ki-kare dağılımına yakınsamaktadır. Panele ilişkin standartlaştırılmış $Z_{N, T}{ }_{N N C}$ istatistiği $T$ ve $N$ sırası ile sonsuza doğru giderken $\mathrm{W}_{\mathrm{N}, \mathrm{T}}^{\mathrm{HNC}}$ istatistiği kullanılarak (Denklem 4) elde edilir (Dumitrescu ve Hurlin, 2012).

\section{BULGULAR}

Ampirik bulgular dört bölümden meydana gelmektedir. Illk bölümde yatay kesit bağımlılığı ve homojenlik, ikinci bölümde eşbütünleşme, üçüncü bölümde modelin tahmini, dördüncü ve son bölümde ise kısa dönemli nedensellik ilişkilerine dair sonuçlar sergilenmektedir. Yatay kesit bağımlılığı $\left(\mathrm{CD}_{\mathrm{LM} 1^{\prime}} \mathrm{CD}_{\mathrm{LM} 2^{\prime}}\right.$ $C D_{L_{3} 3}$ ve $L M_{\text {adj }}$ ) ve homojenlik test (F Testi) sonuçlarına (Tablo 3) göre hem serilerin tek başlarına hem de beraberce modellenmesi durumunda " $\mathrm{H}_{0}$ : Yatay kesit bağımlılığı yoktur" hipotezi her iki ülke grubu için \%1 anlamlılık seviyesinde reddedilememektedir. Ek olarak eğim katsayılarının homojen olduğuna dair kurulan hipotez de her iki ülke grubu için \%1 anlamlılık seviyesinde reddedilmektedir. Bu anlamda serilerde yatay kesit bağımlılığının bulunmasının yanı sıra modele ilişkin eğim katsayıları da heterojendir. Serilere ilişkin heterojenlik ve yatay kesit bağımlılığı durumla- 
rı, uygulanacak birim kök testlerinde de dikkate alınmalıdır. Bu nedenle uygulamadaki seriler heterojenliği dikkate alan IPS (Im vd., 2003) ve heterojenliğin yanı sıra yatay kesit bağımlılığını dikkate alan CADF (Pesaran, 2007) birim kök testlerine tabi tutulmuştur².
Test sonuçlarına göre, serilerde birim kökün olduğuna ilişkin kurulan sıfır hipotezi seviye değerlerinde reddedilemezken, serilerin birinci farkı alındığında reddedilebilmektedir. Bu anlamda seriler hepsinin birinci dereceden durağan olduğu görülmektedir.

Tablo 3: Yatay-kesit Bağımlılığı ve Homojenlik Test Sonuçları

\begin{tabular}{|c|c|c|c|c|c|}
\hline \multirow[t]{2}{*}{$E-7$} & \multicolumn{4}{|c|}{ Yatay-kesit Bağımlılığı* } & \multirow{2}{*}{$\begin{array}{c}\text { Homojenlik }^{* *} \\
\text { F-testi }\end{array}$} \\
\hline & $\begin{array}{c}\mathrm{CD}_{\mathrm{LM} 1} \\
(\mathrm{BP}, 1980)\end{array}$ & $\begin{array}{c}C D_{\mathrm{LM}_{2}} \\
\text { (Pesaran, 2004) }\end{array}$ & $\begin{array}{c}\mathrm{CD}_{\mathrm{LM3}} \\
\text { (Pesaran, 2004) }\end{array}$ & $\begin{array}{c}L_{\text {adj }} \\
\text { (PUY, 2008) }\end{array}$ & \\
\hline FDI & $60.681(0.000)$ & $6.123(0.000)$ & $-3.419(0.000)$ & $9.274(0.000)$ & - \\
\hline TELINV & $75.307(0.000)$ & $8.380(0.000)$ & $-1.867(0.031)$ & $6.788(0.000)$ & $30.784(0.000)$ \\
\hline GDP & $68.515(0.000)$ & $7.332(0.000)$ & $-2.798(0.003)$ & $4.311(0.000)$ & $12.081(0.060)$ \\
\hline TRADE & $54.925(0.000)$ & $5.235(0.000)$ & $-2.708(0.003)$ & $6.420(0.000)$ & $27.986(0.000)$ \\
\hline MODEL & $37.646(0.014)$ & $2.568(0.005)$ & $0.437(0.331)$ & $2.390(0.008)$ & - \\
\hline \multirow[t]{2}{*}{ OECD-14 } & \multicolumn{4}{|c|}{ Yatay-kesit Bağımlılığı* } & Homojenlik** \\
\hline & $\begin{array}{c}\mathrm{CD}_{\mathrm{LM} 1} \\
(\mathrm{BP}, 1980)\end{array}$ & $\begin{array}{c}C D_{\text {LM2 }} \\
\text { (Pesaran, 2004) }\end{array}$ & $\begin{array}{c}\mathrm{CD}_{\mathrm{LM3}} \\
\text { (Pesaran, 2004) }\end{array}$ & $\begin{array}{c}L_{\text {adj }} \\
\text { (PUY, 2008) }\end{array}$ & F-testi \\
\hline FDI & $362.413(0.000)$ & $20.118(0.000)$ & $-2.974(0.001)$ & $-1.602(0.945)$ & - \\
\hline TELINV & $183.841(0.000)$ & $6.882(0.000)$ & $-0.289(0.386)$ & $4.377(0.000)$ & $70.580(0.000)$ \\
\hline GDP & $286.974(0.000)$ & $14.527(0.000)$ & $4.762(0.000)$ & $2.737(0.003)$ & $25.570(0.000)$ \\
\hline TRADE & $226.645(0.000)$ & $10.055(0.000)$ & $0.313(0.377)$ & $4.647(0.000)$ & $53.049(0.000)$ \\
\hline MODEL & $280.460(0.000)$ & $14.044(0.000)$ & $6.670(0.000)$ & $13.021(0.000)$ & - \\
\hline
\end{tabular}

Not:Test istatistik değerlerine ilişkin olasılık değerleri parantez içerisindedir. ${ }^{*}$ Serilere ilişkin $C_{L_{1}}, C D_{M_{2}}, C D_{M_{3}}, L_{2}$ test sonuçları sabit ve trendi bir arada içeren model içindir. ${ }^{* *} \mathrm{fdi}=\mathrm{f}(\mathrm{telinv}, \mathrm{gdp}$, trade) modeli için katsayı homojenliği Wald testi sonuçları.

Tablo 4: Panel CADF Birim Kök Testi Sonuçları

\begin{tabular}{|l|c|c|c|c|}
\hline \multicolumn{1}{|c|}{ E-7 } & \multicolumn{2}{|c|}{ Seviyede } & \multicolumn{2}{c|}{ Birinci Farkta } \\
\hline Seriler & Sabit & Sabit + Trend & Sabit & Sabit + Trend \\
\hline FDI & -1.750 & -2.176 & $-2.791^{* * *}$ & $-2.914^{* *}$ \\
\hline GDP & -1.914 & -2.524 & $-3.872^{* * *}$ & $-3.836^{* * *}$ \\
\hline TELINV & -0.834 & $-2.752^{*}$ & $-3.189^{* * *}$ & $-3.258^{* * *}$ \\
\hline TRADE & -0.716 & -1.737 & $-2.925^{* *}$ & $-2.900^{* *}$ \\
\hline & \multicolumn{2}{|c|}{} & & \multicolumn{2}{|c|}{ Birinci Farkta } \\
\hline OECD-14 & \multicolumn{2}{|c|}{ Seviyede } & Sabit & Sabit + Trend \\
\hline Seriler & Sabit & Sabit + Trend & $-3.942^{* * *}$ & $-4.235^{* * *}$ \\
\hline FDI & $-2.224^{*}$ & -2.414 & $-3.892^{* * *}$ & $-3.999^{* * *}$ \\
\hline GDP & -1.694 & -1.980 & $-3.009^{* * *}$ & $-3.609^{* * *}$ \\
\hline TELINV & -1.511 & -1.609 & $-2.823^{* * *}$ & $-2.831^{* * *}$ \\
\hline TRADE & -1.845 & -2.151 & & \\
\hline
\end{tabular}

Not: CADF testlerinde, maksimum gecikme uzunluğu 4 olarak alınmış ve optimal gecikme uzunluğu Schwarz bilgi kriterine göre belirlenmiştir. ***,** ve * sıfır hipotezinin sırasıyla $\% 1, \% 5$ ve $\% 10$ anlamlılık düzeyinde reddedildiğini göstermektedir. Raporlanan panel istatistiği her bir ülke için hesaplanan CADF istatistiklerinin ortalamasıdır. E-7 ülkeleri için ( $\mathrm{N}=7, \mathrm{~T}=35)$ CADF panel istatistiği kritik değerleri; sabitli modelde -2.57 (\%1), -2.33 (\%5) ve -2.21 (\%10); sabit ve trendli modelde $-3.10(\% 1),-2.86(\% 5)$ ve -2.73 (\%10) (Pesaran 2007). OECD-14 ülkeleri için ( $N=14, T=35)$ CADF panel istatistiği kritik değerleri; sabitli modelde -2.45 (\%1), -2.25 (\%5) ve -2.14 (\%10); sabit ve trendli modelde $-2.96(\% 1),-2.76(\% 5)$ ve -2.66 (\%10) (Pesaran 2007). 
Bu çalışmada seriler arasındaki eşbütünleşme ilişkisi Westerlund ve Edgerton (2007) tarafından heterojen ve yatay kesit bağımlılığı koşullarında kullanılabilen panel eşbütünleşme testi ile (Tablo 5) araştırılmıştır. Hesaplanan $\mathrm{LM}_{N}{ }^{+}$test istatistiği ile eşbütünleşmenin mevcut olduğuna yönünde kurulan $\mathrm{H}_{0}$ hipotezi sınanmaktadır. Yatay kesit bağımlılığının olmadığı varsayımında, sabitli ve trendli model için her iki gelir grubunda da eşbütünleşme hipotezi reddedilmektedir. Yatay kesit bağımlılığı durumunda ise bootstrap prosedürü ile elde edilen kritik değerler kullanılmaktadır. Bootstrap olasılık değerlerine bakıldığında ise eşbütünleşmenin bulunduğuna ilişkin sıfır hipotezi her iki gelir grubu için de reddedilememektedir. Bu anlamda serilerin eşbütünleşme ilişkisi içerisinde olduğu kabul edilmektedir.

Tablo 5: Westerlund ve Edgerton Panel Eşbütünleşme Test Sonuçları

\begin{tabular}{|c|c|c|c|c|c|c|}
\hline$E-7$ & \multicolumn{3}{|c|}{ Sabit } & \multicolumn{3}{|c|}{ Sabit ve Trend } \\
\hline Test & İstatistik & $\begin{array}{c}\text { Asimptotik } \\
\text { p-değeri }\end{array}$ & $\begin{array}{c}\text { Bootstrap } \\
\text { p-değeri }\end{array}$ & İstatistik & $\begin{array}{c}\text { Asimptotik } \\
\text { p-değeri }\end{array}$ & $\begin{array}{r}\text { Bootstrap } \\
\text { p-değeri }\end{array}$ \\
\hline$L M_{N}^{+}$ & 0.493 & 0.311 & 1.000 & 2.791 & 0.003 & 0.960 \\
\hline OECD-14 & \multicolumn{3}{|c|}{ Sabit } & \multicolumn{3}{|c|}{ Sabit ve Trend } \\
\hline Test & İstatistik & $\begin{array}{c}\text { Asimptotik } \\
\text { p-değeri }\end{array}$ & $\begin{array}{c}\text { Bootstrap } \\
\text { p-değeri }\end{array}$ & İstatistik & $\begin{array}{l}\text { Asimptotik } \\
\text { p-değeri }\end{array}$ & $\begin{array}{r}\text { Bootstrap } \\
\text { p-değeri }\end{array}$ \\
\hline$L M_{N}^{+}$ & -0.158 & 0.563 & 1.000 & 2.346 & 0.009 & 1.000 \\
\hline
\end{tabular}

Not: Bootstrap olasılık değerleri 10.000 tekrarlı dağılımdan elde edilmiştir. Asimptotik olasılık değerleri, standart normal dağılımdan elde edilmiştir. Gecikme ve öncül seviyeleri 1 alınmıştır.

Serilerin eşbütünleşik olduklarına karar verildikten sonra eşbütünleşme tahmincileri ile modeldeki katsayılar tahmin edilebilirler. Modelin yatay FMOLS ve DSUR ile tahmini neticesinde elde edilen katsayılar Tablo 6'da sunulmaktadır. FMOLS tahmincisi yalnızca heterojenliği göz önünde bulundururken DSUR tahmincisi heterojenlik ve yatay kesit bağımlılığını beraberce göz önünde bulundurmaktadır. Ancak her iki yöntemle tahmin edilen parametreler karşılaştırıldığında işaret ve büyüklüklerinin birbirine yakın olduğu gözlemlenmektedir. Dinamik SUR tahmincisi için elde edilen katsayılar incelendiğinde E-7 ülke grubu için sabitli modelde TELINV değişkenindeki 1 USD artışın FDI değişkeninde 0.15 USD artışa yol açacağı görülmektedir. Bu anlamda telekomünikasyon yatırımları ile doğrudan yabancı sermaye yatırımları arasında pozitif ve anlamlı bir ilişki bulunmaktadır. Aynı ilişki OECD-14 grubu sonuçlarına bakıldığında da işaret ve anlamlı- lık açısından benzerdir. İkinci ülke grubu için TELINV değişkenindeki 1 USD artışın FDI değişkeninde 1.447 USD artışa yol açacağı görülmektedir. Pozitif ve anlamlı ilişki Choi (2003), Soper vd. (2006) ve Economou (2008) tarafından elde edilen bulguları desteklemektedir. OECD-14 grubundaki etkinin büyüklüğünün E-7 grubundaki etki ile kıyaslandığında yaklaşık on kat daha fazla olması ilave bir bulgudur. Bu durum gelişen ülkeler ile gelişmiş ülkelerin kendilerine çekmekte oldukları yatırımların nitelik fakları ile açıklanabilir. Alexander (2010) tarafından da ortaya konulduğu üzere ülkeler gelişme sürecinin basamaklarında yükselirken ilk aşamalardaki hammadde tabanlı yatırımlara önce sanayi yatırımları ardından yüksek katma değerli bilgi ekonomisi tabanlı yarımlar da eklenmektedir. Böylece gelişmiş ülkeler telekomünikasyon yatırımları aracılığı ile gelişmekte olan ülkelerden çok daha fazla doğrudan yabancı sermaye yatırımı çekebilmektedir.

Tablo 6: Eşbütünleşik Modelin Tahmini

\begin{tabular}{|c|c|l|l|l|}
\hline \multicolumn{2}{|c|}{ FDI } & TELINV & GDP & TRADE \\
\hline \multirow{2}{*}{ E-7 } & DSUR & $0.150^{* *}$ & $0.033^{* * *}$ & 0.001 \\
\cline { 2 - 5 } & FMOLS & $0.186^{*}$ & $0.034^{* * *}$ & -0.012 \\
\hline \multicolumn{2}{|c|}{ FDI } & TELINV & GDP & TRADE \\
\hline \multirow{2}{*}{ OECD-14 } & DSUR & $1.477^{* * *}$ & $0.000^{* * *}$ & $0.043^{* * *}$ \\
\cline { 2 - 5 } & FMOLS & $2.048^{* * *}$ & -0.003 & $0.051^{* * *}$ \\
\hline
\end{tabular}

Not: Katsayılar sabit içeren modelden elde edilmiştir. ${ }^{* * *} p<0.01,{ }^{* *} p<0.05,{ }^{*} p<0.1$. 
Dinamik SUR tahmincisi için diğer katsayılar incelendiğinde ise E-7 grubu için GDP katsayısının 0.033 ve anlamlı iken TRADE katsayısının anlamsız olduğu görülmektedir. Bu anlamda gelişen ülkelerde GSYIH seviyesi doğrudan yabancı sermaye yatırımlarını çekmekte pozitif bir etkide bulunurken dış ticaret hacminin anlamlı bir etkisi bulunmamaktadır. OECD-14 grubu için aynı tahmincinin sonuçlarına bakıldığında GDP katsayısının sıfır ve anlamlı iken TRADE katsayısının 0.043 ve anlamlı olduğu görülmektedir. Bu anlamda gelişmiş ülkelerde GSYiH seviyesindeki artışın söz konusu yatırımlara etkisi yok iken ticaret hacminin pozitif ve anlamlı etkisi bulunmaktadır.

Birinci dereceden durağan seriler arasındaki kısa dönemli nedensellik ilişkileri çalışmanın ek bulguları olarak yorumlanabilir. Dumitrescu ve Hurlin (2012) tarafından heterojen ve yatay kesit bağımlılığı bulu- nan panel veri modelleri için geliştirilen nedensellik testine ilişkin sonuçlar Tablo 7'de sunulmaktadır. Test sonuçları, OECD-14 grubu için Gholami vd. (2005) tarafından elde dilen bulgulara paralel olarak karşılıklı nedensellik ilişkisi bulunduğunu göstermektedir. Gholami vd. (2005) tarafından yapılan aynı çalışmada gelişen ülkelerde, nedenselliğin doğrudan yabancı sermaye yatırımlarından telekomünikasyon yatırımlarına doğru tek yönde bulunduğu ortaya konulmaktadır. Ancak bu çalışmada elde edilen bulgular ilişkinin tek yönlü değil iki yönlü olduğunu ortaya koymaktadır. Bulgular her iki gelir grubu için de seriler arasında karşıııkı kısa dönemli nedensellik ilişkilerinin bulunduğunu göstermektedir. Bu açıdan özellikle gelişen ülkeler için telekomünikasyon yatırımlarının doğrudan yabancı sermaye yatırımlarını ülkeye çekmeyi sağlayan önemli bir politika aracı olduğu görülmektedir.

Tablo 7: Panel Nedensellik Test Sonuçları

\begin{tabular}{|l|c|c|c|}
\hline & $\mathrm{H}_{0}: \Delta \mathrm{TELINV} \rightarrow \Delta \mathrm{FDI}$ & $\mathrm{H}_{0}: \Delta \mathrm{FDI} \rightarrow \Delta \mathrm{TELINV}$ & \\
\hline Gruplar & $\mathrm{W}_{\mathrm{N}, \mathrm{T}} \mathrm{HNC}$ istatistiği & $\mathrm{W}_{\mathrm{N}, \mathrm{T}}^{\mathrm{HNC}}$ istatistiği & Sonuç \\
\hline E-7 & $3.77625^{* * *}$ & $30.5132^{* * *}$ & $\Delta \mathrm{TELINV} \leftrightarrow \Delta \mathrm{FDI}$ \\
\hline OECD-14 & $2.20082^{* *}$ & $10.8271^{* * *}$ & $\Delta \mathrm{TELINV} \leftrightarrow \Delta \mathrm{FDI}$ \\
\hline
\end{tabular}

Not: " $\rightarrow$ "işareti tek yönde " $\leftrightarrow$ " işareti ise her iki yöndeki Granger anlamında heterojen nedenselliği temsil etmektedir. $\mathrm{k}=2$. ${ }^{*} p<0.10$, ${ }^{* *} p<0.05,{ }^{* * *} p<0.01$

\section{SONUÇ}

Dünya genelinde artan küreselleşmenin önemli bir boyutunu ülkeler arasında hareket eden doğrudan yabancı sermaye yatıımları oluşturmaktadır. Ekonomik büyümeye bulunduğu katkı nedeni ile gelişen ülkeler için bu yatıımların ülkeye çekilmesi önemli bir politika hedefidir. Enformasyon ve telekomünikasyon teknolojilerinde meydana gelen gelişmeler ile birlikte bu teknolojilerin ülkeye doğrudan yabancı sermaye yatırımı çekmekte etkili olup olmadıkları cevaplanması gereken birinci sorudur. İkinci soru ise olası etkinin gelişen ve gelişmiş ülkeler için aynı güçte olup olmadığıdır. Bu soruları cevaplamak üzere çalışmada gelişmiş ve gelişmekte olan ülkeler için doğrudan telekomünikasyon yatırımları ile doğrudan yabancı sermaye yatırımları arasındaki ilişki araştırı mıştır. Veriler 7 gelişen, 14 OECD üyesi ülke için 1975-2009 yıllarını kapsayacak şekilde gruplandırılmıştır. Elde edilen bulgular, hem gelişmiş hem de gelişmekte olan ülke grupları için telekomünikasyon altyapısının ülkeye gelen doğrudan yabancı sermaye yatırımlarının pozitif ve anlamlı belirleyicisi olduğunu ortaya koyarak mevcut literatürü desteklemektedir. Sonuçlar ayrıca söz konusu pozitif etkinin gelişmiş ülkelerde gelişmekte olan ülkelerden daha büyük olduğu göstermektedir. Bu durum, enformasyon teknolojileri ile doğrudan yabancı sermaye yatırımları arasındaki pozitif ilişkinin ülkenin gelişme düzeyi arttıkça kuvvetlendiğine yönelik hipotezi de desteklemektedir. Böylece ülkeler gelişmiş ülke olma yolunda ilerledikçe enformasyon ve telekomünikasyon teknolojileri sayesinde daha çok doğrudan yabancı sermaye yatırımı çekebileceklerdir. Çalışmada ayrıca telekomünikasyon yatırımları ve doğrudan yabancı sermaye yatırımları arasındaki kısa dönemli nedensellik ilişkisi de araştııılmıştır. Test sonuçları, OECD-14 grubu için mevcut literatüre paralel olarak karşılıklı nedensellik ilişkisi bulunduğunu göstermektedir. Gelişen ülkeler ele alındığında ise çalışmada elde edilen bulgular ilişkinin literatürdeki gibi tek yönlü değil, OECD-14 grubuna paralel olarak iki yönlü olduğunu ortaya koymaktadır. Her iki ülke grubu için mevcut olan iki yönlü ilişki, söz konusu değişkenler arasında geribildirimle ortaya çıkan bir çarpan etkisi olduğunu göstermektedir. Böylece telekomünikasyon yatırımlarının artması kısa dönemde doğrudan yabancı sermaye yatırımlarını arttıracak, doğrudan yabancı sermaye yatırımlarının artması ile telekomünikasyon yatırımları daha da artacaktır. Ortaya çıkan çarpan mekanizması sayesinde telekomünikasyon yatırımları ile doğrudan yabancı sermaye yatırımlarını arttırmayı hedefleyen politikaların etkinliği bir geri bildirim mekanizmasının olmadığı durumdan daha fazla olacaktır. Sonuç olarak her iki gelir grubun- 
da da telekomünikasyon yatırımları aracılığı ile doğrudan yabancı sermaye yatırımlarını ülkeye çekmeyi hedefleyen politikaların etkili olacağı görülmektedir.

\section{SON NOTLAR}

${ }^{1}$ E-7 Ülkeleri: Brezilya, Çin, Hindistan, Endonezya, Malezya, Meksika, Türkiye. OECD-14 Ülkeleri: Avusturya, Belçika, Kanada, Danimarka, Fransa, Almanya, Yunanistan, İtalya, Japonya, Güney Kore, Portekiz, İspanya, İsveç.

${ }^{2}$ IPS test sonuçları CADF test sonuçları ile paralellik arz etmektedir. Çalışmanın hacmini artıırmamak için IPS test sonuçları raporlanmamıştır.

\section{KAYNAKLAR}

Agarwal, J.P. (1980) "Determinants of Foreign Direct Investment: A Survey” Weltwiltshaftliches, 96: 739-773.

Alexander, D. (2010) "The Relationship between Information and Communication Technologies and Foreign Direct Investment at the Different Stages of Investment Development Path" Unpublished Doctoral Thesis, Hatfield, University of Pretoria Gordon Institute of $\mathrm{Bu}-$ siness Science.

Asiedu, E. (2002) "On the Determinants of Foreign Direct Investment to Developing Countries: Is Africa Dfferent?” World Development, 30(1): 107-119.

Aytun, C. ve Akın, C.S. (2014) "OECD Ülkelerinde Telekomünikasyon Altyapısı ve Ekonomik Büyüme: Yatay Kesit Bağımlı Heterojen Panel Nedensellik Analizi” İktisat İşletme ve Finans, 29(340): 69-94.

Baltagi, B. H. (2005) Econometric Analysis of Panel Data, 3rd Edition, Chichester, John Wiley \& Sons.

Borensztein, E., Gregorio, J.D., ve Lee, J.W. (1998) "How does Foreign Direct Investment Affect Economic Growth?" Journal of International Economics, 45: 115135.

Breusch, T. S. ve Pagan, A. R. (1980) "The Lagrange Multiplier Test andits Applications to Model Specification in Econometrics" The Review of Economic Studies, 47(1): 239-253.

Chakrabarti, A. (2001) "The Determinants of Foreign Direct Investment: Sensitivity Analyses of Cross-Country Regressions” Kyklos, 54(1): 89-114.

Chen, C.H. (1996) "Regional Determinants of Foreign Direct Investment in Mainland China” Journal of Economic Studies, 23(2): 18-26.

Cheng, L.K. ve Kwan, Y.K. (2000) "What are the Determinants of the Location of Foreign Direct Investment? The Chinese Experience" Journal of International Economics, 51: 379-400.
Choi, C. (2003) "Does the Internet Stimulate Inward Foreign Direct Investment?" Journal of Policy Modeling, 25(4): 319-326.

Colecchia, A. ve Schreyer, P. (2002) "ICT Investment and Economic Growth in the 1990s: Is the United States a Unique Case? A Comparative Study of Nine OECD Countries" Review of Economic Dynamics, 5(2): 408-442.

Dumitrescu, E.-I. ve Hurlin, C. (2012) "Testing for Granger Non-causality in Heterogeneous Panels" EconomicModelling, 29(4): 1450-1460.

Economou, P. (2008) "Harnessing ICT for FDI and Development" Global Forum on International Investment III, March 27-28, Paris.

Fielding, D. (1993) "Determinants of Investment in Kenya and C'ote d'Ivoire" Journal of African Economies, 2(3): 299-328.

Fielding, D. (1997) "Adjustment, Trade Policy and Investment Slumps: Evidence from Africa” Journal of Development Economics, 52: 121-137.

Gholami, R., Lee, S.Y.T. ve Heshmati, A. (2005) "The Causal Relationship between ICT and FDI" WIDER Research Paper, No:2005/26.

Granger, C. W. J. (1969) "Investigating Causal Relations by Econometric Models and Cross-spectral Methods" Econometrica, 37(3): 424-438.

Greene, J. ve Villanueva, D. (1991) "Private Investment in Developing Countries" IMF Staff Papers, Vol. 38.

Im, K. S., Pesaran, M. H. ve Shin, Y. (2003) "Testing for Unit Roots in Heterogeneous Panels" Journal of Econometrics, 115(1): 53-74.

Ketteni E., Kottaridi, C. ve Mamuneas, T. (2010), "Information and Communication Tehnology and Foreign Direct Investment" Annual Meeting of the Austrian Economic Association, May 14-15, Vienna.

Loree, D.W. ve Guisinger, S.E. (2009) "Policy and Non-Policy Determinants of US Equity Foreign Direct Investment" Journal of International Business Studies, 26(2): 281-299.

Mark, N. C., Ogaki, M. ve Sul, D. (2005) "Dynamic Seemingly Unrelated Cointegrating Regressions" The Review of Economic Studies, 72(3): 797-820.

McCoskey, S. ve Kao, C. (1998) "A Residual-based Test of the Null of Cointegration in Panel Data" Econometric Reviews, 17(1): 57-84.

Ndikumana, L. (2000) "Financial Determinants of Domestic Investment in Sub-Saharan Africa: Evidence from Panel Data” World Development, 28(2): 381-400. 
Pedroni, P. (2000) "Fully Modified OLS for Heterogenous Cointegrated Panels" B. Baltagi (ed.) Advances in Econometrics, Bingley, Emerald.

Pesaran, M. H. (2004) “General Diagnostic Tests for Cross Section Dependence in Panels" Institute for the Study of Labor Working Papers, No:1240.

Pesaran, M. H. (2007) "A Simple Panel Unit Root Test in the Presence of Cross-section Dependence" Journal of Applied Econometrics, 22(2): 265-312.

Pesaran, M. H., Ullah, A. ve Yamagata, T. (2008) “A Bias-adjusted LM Test of Error Cross-section Independence" Econometrics Journal, 11(1): 105-127.

Pesaran, M. H. ve Yamagata, T. (2008) "Testing Slope Homogeneity in Large Panels" Journal of Econometrics, 142(1): 50-93.

Pohjola, M. (2002) “The New Economy in Growth and Development" Oxford Review of Economic Policy, 18(3): $380-396$.

Soper, D.S., Demirkan, H., Goul, M. ve Louis, R.S. (2006) "The Impact of ICT Expenditures On Institutionalized Democracy and Foreign Direct Investment in Developing Countries" $39^{\text {th }}$ Hawaii International Conference, Jan 4-7, Hawaii.
Terpstra, V. ve Yu, C.M. (1988) “Determinants of Foreign Investment of US Advertising Agencies" Journal of International Business Studies, 19(1): 33-46.

Uçan, O. ve Öztürk, Ö. (2011) "Financial Determinants of Investment for Turkey", Journal of Economic and Social Studies 1(1): 83-110.

Veeramacheneni, B., Vogel, R. ve Ekanayake, E.M. (2008) "Information Technology, FDI and Economic Growth: An India Case Study" Southwestern Economic Review, 35(1): 95-112.

Wai, T. U. ve Wong, C. H. (1982) “Determinants of Private Investment in Developing Countries" Journal of Development Studies, 19 (1): 19-36.

Westerlund, J. ve Edgerton, D. L. (2007) "A Panel Bootstrap Cointegration Test" Economics Letters, 97(3): 185-190. 